\title{
Hu Shih About Education
}

\author{
Valery A. Kiselev, ${ }^{1, *}$ \\ ${ }^{1}$ Peoples' Friendship University of Russia (RUDN University), 6 Miklukho-Maklaya st., Moscow 117198, Russian \\ Federation \\ "Corresponding author. E-mail: kiselev-va@rudn.ru
}

\begin{abstract}
For centuries, China has been extremely attentive to education relating to Confucianism, but at the turn of the 19th and 20th centuries, under the pressure from the West, China was forced to begin the process of modernization and westernization of all spheres of life, including education. In the first half of the 20th century, one of the important directions of the modernization of education in China was introduced by Hu Shih - a politician, philosopher, diplomat and teacher. He sharply criticized traditional foundations for their inertness, and extolled modern American ideas, but nevertheless, he combined the traditional Confucian and American pragmatic approaches to education. Hu Shih's ideas about education continue to resonate in China to these days.
\end{abstract}

Keywords: philosophy, Chinese philosophy, philosophy of education, history of Chinese philosophy,

education in China, Hu Shih

\section{INTRODUCTION}

China has traditionally payed great attention to education. The fundamental Confucian text the Analects of Confucius starts with the words "Is it not pleasant to learn with a constant perseverance and application?" [1]. The idea of the importance of learning and knowledge, respect for written culture can be traced throughout the Chinese history. In 605 (the reign of the Sui Dynasty) a system of civil service examination (keju, 科举) was introduced in China. This Imperial examination was obligatory for getting access to official positions and, therefore, fixed the prominent role of education for state administration. In later Chinese history the examination system was used by almost all ruling dynasties in China, including foreign ones, for example, the Jurchen Jin dynasty (1115-1234), the Mongol Yuan dynasty (1271-1368) or the Manchu Qing dynasty (1644-1912). Before 1905, when the Imperial examination was abolished, the examination system was not just the engine for education, but the basis for the existence of a strong empire, too, as the system made it possible to select the most worthy, educated individuals, and, at the same time, those who were loyal to the state [2], [3]. Confucianism, as the core of the examination system, determined the content and form of education.

In the second half of the 19th century and at the beginning of the 20th century, the need for reforming

*Fund: The reported study was funded by RFBR according to the research project 20-511-S52002 MHT_a "Philosophy of Being Human as the Core of Interdisciplinary Research". the education system became very clear to the Chinese intellectuals. Boisterous discussions were held about the ways and means of such reforming, involving the widest range of ideas from the extremely traditionalist to radically liberal.

The views on education of the teacher, philosopher, diplomat, poet $\mathrm{Hu}$ Shih became very popular during the second decade of 20th century. His approach united seemingly distant, but essentially extremely close ideas of the pioneer of Chinese thought Confucius and the American pragmatic philosopher Dewey. These concepts by $\mathrm{Hu}$ Shih and their evolving value are the focus of the present paper.

\section{EDUCATION AND MODERNISATION IN CHINA IN EARLY 19 $19^{\mathrm{TH}}-$ BEGINNING OF $20^{\mathrm{TH}}$ CENTURY}

The First Opium War began in 1840. It was a turning point for Chinese history. As a result of a series of military defeats during the massive advance of the West, China lost a part of its sovereignty and faced the question how to maintain independence, save national and cultural identity. The problem was even more global - how could China survive? Among the educated people of that time, it was generally accepted that only reforms could be a way out. The educated Chinese believed that on the path of self-reinforcement (ziqiang, 自强) China needs to learn from the West. Chinese intellectuals, especially those studying abroad, firstly in Japan, then in Europe and the USA, saw the power and wealth of Japan, European countries and the USA. They compared what they saw with the situation in China, 
with its backwardness and poverty, and came to a conclusion that without reforms China would die.

The situation was complicated by the fact that in 1905 China abandoned the Imperial examination system, which determined the principles and direction of education for centuries. On the one hand, this fact favored the development of a new education. On the other hand, it deprived China of a ready-made system for training and selecting civil servants, and most importantly, it destroyed the ideal of an educated person, that was being developed over 1300 years. In the framework of Confucian thought and the examination system, it was clear what a person should be, what he should do in order to be educated and therefore demanded by the state system and, ultimately, to be realizing the goal of "being human". After the abolition of the examination system, the answer to the question "what does it means to be human" lost its obviousness.

The main motive for creating new educational institutions was the idea of patriotism and the salvation of the state. At the initial period, the creators of these new 'schools' tried to combine tradition and innovation: only technical and natural sciences were taught according to the Western standards, but social and humanitarian sciences were still taught in accordance with the traditional canons.

At the beginning of the 20th century, despite half a century of attempts of self-reinforcement and modernization, China still has not made a choice of the way of development. The issue of organization, orientation, content and quality of education has traditionally been considered by Chinese intellectuals among the most important issues in the reorganization of the entire social system and improving the quality of life. Discussions on the essence and principles of education were unfolding on the pages of magazines in the first quarter of the 20th century [4], [5]. Many intellectuals, such as Chen Duxiu (陈独秀, 1879-1942), Li Dazhao (李大钊, 1888-1927), Hu Shih (胡适, 18911962) and others rejected Confucian claims to define the ideal of a human person. They saw in Confucianism as a whole, in Confucian rules, virtues and Confucian education, the reasons why China is lagging developed countries. These intellectuals attempted to offer alternative answers to the question of what it means to be human.

One of those who called for turning to the West in order to create a new ideal of a person for China was $\mathrm{Hu}$ Shih - a philosopher, educator, diplomat and social activist of China in the first half of the 20th century. In his works, he turned to various fields of humanitarian knowledge: philosophy, religion, literature, history, etc. $\mathrm{Hu}$ Shih's interest to education was based on a synthesis of the eastern and western attitudes as a result of, on the one hand, his respect for learning being traditional for an educated Chinese, and on the other, of the influence of Hi Shih's American teacher John Dewey (18591952), who was one of the prominent figures in education in the US at the end of the 19th and beginning of the 20th centuries [6], [7], [8], [9]. Attention to the education was also fueled by Hu Shih's practical activities as a professor and then rector of Peking University.

Based on a synthesis of traditional and Western approaches, $\mathrm{Hu}$ Shih sought to determine what kind of a new person should be required in the new China.

\section{CHINESE INTELLECTUALS IN SEARCH OF KNOWLEDGE}

Initially $\mathrm{Hu}$ Shih received a classic traditional home education. Then he studied in a number of educational institutions of a new type, where, in addition to traditional knowledge, he was taught English and the basics of Western natural sciences. In 1904, at age of 13, he entered Meiji Xuetang (梅溪学堂) founded in 1878 by the creator of modern primary education in China Zhang Huanlun (张焕纶, 1846-1904). Meiji Xuetang was the first school of a new model in Shanghai, where, besides the traditional disciplines, they taught English and arithmetic. In 1905, Hu Shih transferred to Chengzhong xuetang (澄衷学堂) founded by a pioneer in the modern Chinese hardware industry Ye Chengzhong (叶澄衷, 1840-1899). It was the first school founded by a Chinese in China with a classroom education system. The first director of Chengzhong school was Cai Yuanpei (蔡元培, 1868-1940), the future Minister of Education of the Republic of China. In 1906 $\mathrm{Hu}$ Shih entered the newly created Zhongguo gongxue (China Academy or China Public Institute, 中国公学) [10]. This prototype of the modern Chinese universities was founded after banning the education of Chinese students in Japan in November 1905. After returning to their homeland students decided to create a new educational institution in Shanghai, they hoped it could become a "Chinese "Waseda University" [11], [12], [13]. Later in 1928, Hu Shih became the rector of his alma-mater - China Academy [14].

In these educational institutions of the new type, young $\mathrm{Hu}$ Shih studied the basics of Western natural sciences and English, as well as traditional Chinese humanities.

Very important for his further educational and scientific activities was a fact that $\mathrm{Hu}$ Shih was fortunate to become a member of the group of Chinese intellectuals who studied abroad, gaining invaluable personal experience of living in the environment of Western culture. Most part of Chinese students who were sent abroad at the beginning of the 20th century 
mastered the technical side of Western civilization, but $\mathrm{Hu}$ Shih consciously decided to receive education in the sphere of liberal arts. He went to study to America sponsored by the so-called 'Boxing fund' established in frames of contribution imposed on China according to the 'Final Protocol' of September 7, 1901, after the defeat of the Yihetuan rebellion.

In 1908 the US government suggested that a part of the indemnity was to be used to form a special Fund for "the development of education in China", in particular, to cover the costs for training Chinese in the United States. Thus, the expansion of American ideological influence on China should have been carried out at the expense of China itself. At the same time, it was very important and helpful for China, because the modernization of the country objectively required the skilled personnel. In 1909, the first group of Chinese students went to the US with the scholarship of the Boxing Fund. On August 16, 1910, Hu Xijiang, later known as Hu Shih, was included in the second group of students to study in the United States. It was around that time that he changed his name to Shih (适, "Fitted", "Adapted"), reflecting his fascination with evolutionism, as $\mathrm{Hu}$ Shih read the Chinese translation of Huxley's "Evolution and Ethics" by Yan Fu (严复, 1854-1921) and was charmed by the phrase "survival of the fittest" [15].

In the USA, Hu Shih first studied at the Cornell University College of Agriculture, but then he transferred to the College of Sciences and Arts. In 1915-1916 he studied at Columbia University and defended his doctoral thesis under the supervision of John Dewey.

After returning to China, $\mathrm{Hu}$ Shih actively joined the "New culture movement". The progressive-minded Chinese intellectuals united around 'Xin Qingnian' (New Youth) magazine. On the pages of this magazine they raised questions about the fate of Chinese culture and Chinese literature. The authors of the magazine sharply criticized the old literature, which was far from the modern demands of society, the traditional social system and ideology of China, opposed the old education system, etc. Hu Shih became one of the spiritual leaders of the 'May Fourth Movement' together with Cai Yuanpei, Chen Duxiu and Li Dazhao. This movement began with protests of Beijing students against the decision of the Versailles Conference (April $28,1919)$ to transfer Germanic possessions in Shandong to Japan, but very quickly the Movement went beyond the students' strike. Students, professors, intellectuals raised not only political questions, but touched upon a broader subject of the reassessment of traditional values and norms, democratic and humanistic principles and ideals.
One of the most important issue of the movement, for $\mathrm{Hu}$ Shih and other leaders, was education and the role of an educated person in the transformation of the society.

\section{ROOTS OF HU SHIH'S CONCEPT OF EDUCATION}

$\mathrm{Hu}$ Shih was called the overall (or radical) Westernizer (quanpan xihua, 全盘西化). In the Chinese historiography of the 30-40s and especially 50s of the 20th century, a lot of $\mathrm{Hu}$ Shih's ideology opponents saw the origins of his theories only in the Western ideas, mainly in American instrumentalism. However, despite speaking about Confucianism mainly negatively, when referring to education, $\mathrm{Hu}$ Shih often used Confucian ideas and highly valued Confucian contribution to the education.

In works on education, $\mathrm{Hu}$ Shih payed great attention to traditional Chinese education. $\mathrm{He}$ demonstrated the importance of such an education for the formation of an educated person, but, at the same time, he fiercely criticized it for backwardness, inertness and inability to adapt to the contemporary situation.

One of Hu Shih's brightest articles on this subject is "On Home Education", which is devoted to the basis of traditional Chinese education - family education. Young $\mathrm{Hu}$ Shih (an article was published in the Jingye Xunbao newspaper in September 1908 when he was only 17 years old) was extremely emotional: there are a lot of exclamative particles, exclamation marks and rhetorical questions in the article. The author was lamenting the fate of "the hundreds of thousands of Chinese people who live in a world without any knowledge ... like slaves or animals" [16]. Hu Shih saw the reason for this in home education. In the article, he wrote that in traditional China, great attention was paid to home education, from the youngest years the child was aimed at lifelong learning. Hu Shih quoted the proverb "Three years determine eighty." Parents taught the child from childhood, and it was a strict system of education: "it was clear what the child does at six years old, at seven, at eight and nine. And only from ten years old he begins to study under the guidance of a teacher" [16]. Hu Shih saw the basis of home education in the figure of a mother. Because it was she who laid the foundation for further training. In this case, one cannot help but recall such iconic personalities in Chinese culture as Confucius and Mencius - both patriarchs of Confucianism were raised by their mothers.

$\mathrm{Hu}$ Shih pointed out that in Ancient China, home education yielded positive results, but by the moment it was outdated and as it was, it could no longer be the basis for modern education. Hu Shih saw the development of education for women as one of the 
most important measures for the reform of home education. It was the mother who was the main teacher in home education system, therefore, in order to develop, in order to be modern, it was necessary that women received education to enable them to properly educate their children. Hu Shih finished the article in line with the Chinese tradition, he wrote: "and if you give your son a bad education, spoil him, then whom you can rely on when you are old age" [16].

In 1959, several years before his death, Hu Shih published an article entitled "Materials on the history of education in China," in which he called the "Unofficial History of Scholars", "The Analects of Confucius", and "Mencius" as the main sources for Chinese education. He noted that starting with "The Analects" one can trace the history of education in China: "The dialogues of Confucius and his followers in "The Analects" are truly a living education" [17]. The other cited by $\mathrm{Hu}$ Shih important text "The Unofficial History of Scholars" is a classic novel written by Wu Jingzi (吴敬 梓, 1701-1754) in 1750. This work, according to $\mathrm{Hu}$ Shih, "not only talks about the education system, life and relationships between teachers and students, but also talks about what kind of character and spiritual qualities this system of education and the relationship between teachers and students brings up in students" [17].

It can be seen from the above that there is no doubt that traditional Chinese education had great influence on $\mathrm{Hu}$ Shih. At the same time, he was greatly influenced by his teacher J. Dewey. After returning to China, Hu Shih became a consistent evangelist of Dewey's ideas, wrote articles about his ideas, and when Dewey arrived in China, Hu Shih was his interpreter.

At the end of the 19th - beginning of 20th century China had an extremely unusual intellectual situation. Within a very short period, in almost three decades, Chinese educated people became acquainted with the most prominent philosophical and socio-political teachings of the West. The teachings of Plato and Aristotle, Kant and Hegel, the evolutionary theory of Darwin, the doctrines of Nietzsche, Schopenhauer and others, century after century were replacing each other in the philosophical arena of Western civilization, but for China all these concepts were equally "new" and expanding the reader's view of the possibilities of theoretical reflection. One of the most influential philosophical movements that captured the minds of Chinese intellectuals, albeit for a short time, was pragmatism in the instrumentalist version of John Dewey.

Chinese intellectuals in the early 20th century were attracted to pragmatism by restrained philosophical optimism, an actual appeal to common sense, the concept of an intermediary function of truth and its experimental nature, which made it possible to combine the past with the present and was extremely important for China, which sought to modernize, but also passionately wished to preserve national and cultural identity. The Chinese elite was even more interested in the fact that pragmatism was presented as a philosophical system, which also promised to provide for a reliable mechanism that claimed universal applicability for the development of vital practical solutions.

\section{EDUCATION AND THE DIALOGUE OF EAST AND WEST}

Almost all philosophical discussions in China of the 20-30s of the 20th century were somehow related to the problem of dialogue between East and West. For Chinese thinkers of the early 20th century the problem of correlation of cultures of East and West became not just a topic of theoretical constructions, but an important social issue determining the future of China and the possibility of its existence.

The Chinese intellectuals had various views on the future of the Chinese culture, from rigidly traditionalist to extremely pro-Western. As for the traditionalist wing of philosophical and socio-political thought, not all thinkers went back to the position of zealots advocating for the purity of the national tradition. However, traditionalist thinkers of different directions were unanimous in recognizing the unconditional superiority of Chinese culture, in which spiritual values were placed higher than material ones. Superiority over Western culture, which was considered to be centered on the utilitarian issues of human existence, was emphasized. These 'zealots' recognized the meaning of human life to be a moral improvement, "ennoblement of the spirit."

'Moderately traditionalist' concept of Liang Shuming (梁淑敏, 1893-1988) expounded in “The Cultures of the East and West and their philosophies" was quite popular in the early 20 s of the 20th century. Liang Shuming defended the special, messianic role of the Chinese tradition: "The future world culture is the revived culture of China." [18] He identified three main types of cultures, i.e. Western, Chinese and Indian, corresponding, according to him, to the three phases of the development of the world culture. It was supposed that the genesis would follow a certain sequence: from the dominance of the Western type of culture to the dominance of the Chinese type and further to the dominance of the Indian one. The West has already exhausted the possibilities of its development and was considered, therefore, to be ready for the perception of the values of Chinese culture, argued Liang Shuming, seeing these values mainly in renewed Confucianism. The initial premise of Liang Shuming's theory was that any culture is condemned if it is not able to become a 
world culture, and vice versa, if it is viable, it should go beyond the borders of one country and gain a worldwide character [18].

One of the most ardent opponents of this concept was $\mathrm{Hu}$ Shih. For the latter, Western culture was something more than a passing stage in the development of mankind.

Acquaintance with Western culture began for $\mathrm{Hu}$ Shih with translations of $\mathrm{Yan} \mathrm{Fu}$ and the works of Liang Qichao. From 1910 to 1917, when Hu Shih studied in the USA, he, as he wrote in his diaries, not only studied history and philosophy at the university, but also immersed himself in the life of American society, comprehending its political and religious values from within. $\mathrm{Hu}$ Shi claimed that the study of Western philosophy taught him to "think sincerely and speak sincerely," and had a huge impact on his worldview and thinking [19].

$\mathrm{Hu}$ Shih believed that the activities of traditionalist thinkers adversely affected the development of Chinese society and culture. In the article "Our attitude to Western civilization", he called the recognition of Western civilization as "material", and Eastern as "spiritual" to be "the most baseless and most harmful misconception". In his opinion, since the eastern peoples received the pressure from the western nations, this theory has been used to "self-complacency" of the eastern. One of the reasons for revival of this concept was the post-war disappointments of the Western intellectuals in "modern scientific civilization." Hence the immoderate enthusiasm of Western scholars for the "spirituality" of eastern civilization, was taken up by the intelligentsia of the East [20].

In 1930, in an article "On My Thinking”, Hu Shih ironicized: "Boarding a wooden raft we can't boastfully call ourselves spiritual civilization and mock the 50-ton ship as a material civilization." He pointed out that many of Chinese scientists do not have a clear idea of the concept of "civilization." He insisted that each civilization consisted of the material and spiritual elements, and a civilization that would be completely material or absolutely spiritual never existed. Moreover, in order to achieve the level of "spiritual" civilization, it must first provide for an appropriate material level. "Spiritual civilization has to be built on basis of material civilization. To increase people's ability to enjoy in the material sphere, to increase material conveniences and comfort - all this is aimed at the release of human abilities". The peculiarity of the modern Western civilization was that it recognized the importance of "enjoying the material" (wuzhi de xiangshou, 物质的享受). Moreover, Hu Shih asserted that the Western civilization set the achievement of happiness as a goal of human life and considered poverty and disease as a crime [21].
According to $\mathrm{Hu}$ Shih, it was obvious that the Western countries tried to develop spiritual aspect of civilization on basis of its material aspect, with science as a special element combining material and spiritual. And "the spirit of science is the search for truth." [21]

The most important feature of Western civilization, according to $\mathrm{Hu} \mathrm{Shi}$, was that it "did not know satisfaction" (buzhi zu, 不知足), i.e. it did not recognize the limit of growth of human needs, including intellectual and cognitive, in contrast to the civilizations of the East, which in one way or another set the limits of sufficiency of these needs, including in the sphere of comprehension of the world. That is why, according to $\mathrm{Hu}$ Shih, people of the West were trying to change nature and society. "The full use of human knowledge and ability to search for truth and liberate the soul ...was to change the material environment, to reform the social and political system, to strive for the greatest happiness of mankind - such a civilization must be able to satisfy the spiritual needs of mankind; such a civilization is a spiritual civilization, a truly ideal civilization, and definitely not a material civilization." [21].

\section{CONCLUSION}

In 1949, Hu Shih moved to Taiwan and his ideas were fiercely criticized in China, especially in the 50s, when the "Big Campaign of Criticism of $\mathrm{Hu}$ Shih" was launched [22]. In China, $\mathrm{Hu}$ Shih did not have followers and successors either in the philosophical sphere of the development of pragmatism, or in the field of his educational policy. Since the 1950s, China began to actively use the Soviet experience in education and Hu Shih's instrumentalist ideas became unwanted, and his views on the role of Confucianism in education, which were considered extremely radical in 30 s and $40 \mathrm{~s}$, were not enough critical at all for New China in 50 s.

Despite the predominance of Marxist-Maoist views in the social sciences of China in the second half of the 20th century, many historians, sometimes implicitly, but nevertheless continued to use and develop views based on the ideas of $\mathrm{Hu}$ Shih, including the "doubt in antiquity," a critical attitude to history and historical sources, etc. [23].

In Taiwan, $\mathrm{Hu}$ Shih organized and headed Academia Sinica and paid great attention to the development of schools and universities. In PRC in the 80s, as ideological censorship weakened, an interest to $\mathrm{Hu}$ Shih, including to his concepts of education, revived. Over the past decades, many works have been published and researchers not only studied his views on education, but also argued about how these views could be applied to improve modern education in China nowadays [24]. 
Hu Shih lived 71 years, and he devoted 60 years of his life to education: at first, he mainly studied himself, then he mainly taught others. He was the director of China College, the rector of Peking University and Nankai University, and president of the Academia Sinica. In 1959, he began the article "Sources of Education in China" in the spirit of radical criticism, typical for both Chinese tradition and American pragmatism, with the words: "I am a person who does not understand education" [17].

\section{References}

[1] The Analects of Confucius. CreateSpace Independent Publishing Platform, 2016. P. 4.

[2] Elman Benjamin. A Cultural History of Civil Examinations in Late Imperial China. Berkeley and Los Angeles: University of California Press, 2000

[3] Miyazaki Ichisada (1976), China's Examination Hell: The Civil Service Examinations of Imperial China. New Heaven: Yale University Press, 1981

[4] Zhang Junmai. Rensheng guan (Philosophy of life) //Qinghua Weekly. No 272. (March 1923).

[5] Hu Shih. Sunxingzhe yu Zhang Junmai (Sun xingzhe and Zhang Junmai) // Nuli Weekly. No. 53. (May 12 1923)

[6] $\mathrm{Hu}$ Shih. Duwei lun sixiang (Dewey about thinking). // Hu Shih quanji (Complete edition of Hu Shih's works). Hefei: Anhui jiaoyu chubanshe, 2003. Vol. 7. Pp. 420-447.

[7] $\mathrm{Hu}$ Shih. Duwei zhexue (Philosophy of Dewey) // Hu Shih quanji (Complete edition of $\mathrm{Hu}$ Shih's works). Hefei: Anhui jiaoyu chubanshe, 2003. Vol. 8. Pp. 449-458.

[8] Hu Shih. Duwei de jiaoyu zhexue (Philosophy of education of Dewey) // Hu Shih quanji (Complete edition of $\mathrm{Hu}$ Shih's works). Hefei: Anhui jiaoyu chubanshe, 2003. Vol. 20. Pp. 3648.

[9] Hu Shih. Duwei zhi daode jiaoyu (Moral education of Dewey) // $\mathrm{Hu}$ Shih quanji (Complete edition of Hu Shih's works). Hefei: Anhui jiaoyu chubanshe, 2003. Vol. 20. Pp. 48-56.

[10] Luo Zhitian. Shifts of Power: Modern Chinese Thought and Society. Brill, 2017. Pp. 148-150.

[11] Guo Hanmin. Hunan xinhai geming renwu zhuanlue (Short biographies of persons of Xinhai revolution in Hunan). Beijing: Beijing Shuju, 2011.

[12] Shang Jinlin. Ye Shengtao huazhuang (A Pictorial Biography of Ye Shengtao). Nanchang: Jiangxi renmin chubanshe, 2015.

[13] Hu Shih. Zhongguo gongxue xiao shi (The history of Chinese Academy)// Hu Shih quanji (Complete edition of Hu Shih's works). Hefei: Anhui jiaoyu chubanshe, 2003. Vol. 20. Pp. 143152.

[14] Hu Shih. Huiyi Zhongguo gongxue (Remembering the Chinese Academy) // Hu Shih quanji (Complete edition of Hu Shih's works). Hefei: Anhui jiaoyu chubanshe, 2003. Vol. 20. Pp. 279283.

[15] Xue Chen. Ziyou de xingzhe - Hu Shi (Free walker - Hu Shih). Beijiing: Zhonghua gongshang lianhe chubanshe, 2017.

[16] $\mathrm{Hu}$ Shih. Lun jiating jiaoyu (About home education). // Hu Shih quanji (Hu Shih full collection of writings). Hefei: Anhui jiaoyu chubanshe, 2003. Vol. 20. Pp. 3-5

[17] $\mathrm{Hu}$ Shih. Zhongguo jiaoyu shi de ziliao (Materials for the History of Education in China). // Hu Shih quanji (Complete edition of Hu Shih's works). Hefei: Anhui jiaoyu chubanshe, 2003. Vol. 20. Pp. 343-344.
[18] Liang Shuming. Dongxi wenhua ji qi zhexue (The Cultures of the East and West and their philosophies). Shanghai: Shanghai renmin chubanshe, 2006.

[19] Hu Shih. Riji 1915-1917 (Diaries 1915-1917) // Hu Shih quanji (Complete edition of Hu Shih's works). Hefei: Anhui jiaoyu chybanshe, 2003. Vol. 28

[20] Hu Shih. Women duiyu xiyang wenming de taidu (Our attitude to Western civilization) // Hu Shih quanji (Complete edition of Hu Shih's works). Hefei: Anhui jiaoyu chubanshe, 2003. Vol. 3.

[21] $\mathrm{Hu}$ Shih. Jieshao wo zijide sixiang (On My Thinking) // $\mathrm{Hu}$ Shih quanji (Complete edition of $\mathrm{Hu}$ Shih's works). Hefei: Anhui jiaoyu chybanshe, 2003. Vol. 1.

[22] Hu Shi sixiang pipan (Critics of ideas of Hu Shih). Vol. 1-8 Beijing: Shenghuo dushu xinzhi sanlian shudian, 1955.

[23] Gu Jiegang. Qin Han de fangshi yu rushing (Qin and Han Dynasties Alchemists and Confucian Scholars). Shanghai: Shanghai guji chubanshe, 1983.

[24] $\mathrm{Hu}$ Shi yu xiandai zhongguo wenhua zhuanxin (Hu Shih and contemporary turn in Chinese culture). Liu Qingfeng ed. Hong Kong: Xianggang zhongwen daxue chubanshe, 1994. 